\title{
VARIATION OF THE EXTERIOR IN THE BULGARIAN SCREW-HORNED LONGHAIRED GOAT FROM TWO DISTRIBUTION AREAS
}

\author{
A. Vuchkov* \\ Agricultural University, Plovdiv, Bulgaria
}

\begin{abstract}
The Bulgarian Screw-horned longhaired goat is a local breed, distributed in the mountainous regions of Bulgaria. The largest compact herds with preserved breed type of the animals are differentiated into two main habitats.

I. The region of Southwestern Bulgaria - mainly in the southern and western border mountains of the Blagoevgrad region (the slopes of Southern Pirin, Slavyanka, Ograzhden, Malashevska mountains).

II. The region of Western Stara Planina (settlements along the northern slopes) - mainly the Vratsa and Teteven regions. Exactly from these two areas (Teteven region and settlements in the border regions of Blagoevgrad region) in the 1968 year Professor Altman selects animals for conservation work with this breed in the GDR (1). Initial monitoring of the population shows some variation in the exterior signs of specimens in the two native distribution areas. This requires a detailed study and comparative analysis of the exterior in specimens from the respective areas. For the purposes of the study, complete measurements and descriptions of the exterior were performed in 50 goats and 20 bucks, respectively, from each areal. The Bulgarian Screw-horned longhaired goat from the area of Northwestern Stara Planina was larger and more massive than the animals from the area of Southwestern Bulgaria. The heigh at withers for the goats from the Vratsa region was $74.42 \mathrm{~cm}$ and $66.06 \mathrm{~cm}$ in goats from the Sandanski region. This sign in the bucks also shows a difference of almost $10 \mathrm{~cm}-83.75$ and 72.45 , respectively for male animals from the two regions. The differences were proven with a high degree of probability. The goats from the area of Northwestern Stara Planina has a longer and broader head, the ears were proven to be longer, than in the animals from Southwestern Bulgaria. The horns of both male and female specimens from the Vratsa region were extremely rough and massive. The differences were proven with a high degree of probability.
\end{abstract}

Keywords: Local goat breeds, Exterior measurements, Bulgarian screw-horned longhaired goat

\section{INTRODUCTION}

With the growing of the interest to the local goat breeds and their sustainable conservation, the conditions of these genetic resources in our country were reassessed. In our country, systematic, controlled breeding activity with the breed Bulgarian screw-horned longhaired goat began relatively recently, although the breed is known to foreign specialists, with this name, since the early 60's (1). The author expresses an opinion on the endangerment and distribution of the breed, quoting the words of Prof. Altman - "In the autumn of 1968 we had to look in vain in many places for specimens of

*Correspondence to: Atanas Vuchkov' Agricultural University, 4000 Plovdiv, Bulgaria, 12, Mendeleev Str.'E-mail: a_vu@abv.bg such local Bulgarian goats. Most often we found different stages of crosses with the imported breeds of goats. On the hills of Stara Planina, around the town of Teteven, we finally found original Bulgarian screw-horned goats. In the vicinity of Blagoevgrad town, near the Yugoslavia border, there is a hilly area with peaks over $1000 \mathrm{~m}$. There were only a few houses on each hill, so we cannot speak of a compact settlement. We had to climb for a long time when we met a mixed flock of sheep and goats have appeared. There were also original Bulgarian screw-horned goats. At the end of 1968, 22 Bulgarian screw-horned goats arrived at the Erfurt freight station".

The first scientific report for our country, and the first more detailed studies of this local goat breed, also dated back recently (2-6). The 
Bulgarian screw-horned longhaired goat is an indigenouse breed, widespread mainly in the mountainous regions of Bulgaria. The largest compact herds of animals with preserved breed type were differentiated into two main areas:

I - the region of Southwestern Bulgaria - mainly in the southern, and western border mountains of the Blagoevgrad region (the south slopes of Pirin, Slavyanka, Ograzhden, Malashevska mountains). II - the region of Northwestern Bulgaria -the Western Stara Planina (the settlements on the northern slopes) - mainly the Vratsa, Botevgrad, and Teteven regions.

Namely from the Teteven region, and from settlements in the border areas of the Blagoevgrad region in 1968 Professor Altman selects animals for conservation work with the breed in the former GDR (1). During the initial monitoring of the population, was noticed some intra-breed variation of the exterior of specimens from the respective regions. Variation in the exterior features is considered as normal in the indigenous populations of domestic animals. The factors that are responsible for this, can be environmental conditions, and breeding work by the individual breeders. The aim of the present work is a detailed study, comparative analysis of the exterior, and variations in specimens of the breed in the two natural distribution areas.

\section{MATERIAL AND METHODS}

The study covered 3 representative herds from each of the two distribution areas for the breed. For the area of Northwestern Bulgarian 3 herds were visited in settlements near the towns of
VUCHKOVA.

Vratsa and Botevgrad. For the area of Southwestern Bulgaria, 3 herds were visited in settlements near the towns of Kresna and Petrich. Full measurements and exterior descriptions were made of 100 female, and 40 male complete growth specimens (50 females and 20 males from each region). For exterior measurements were used: a small Lidtin cane, a Wilkens compass, and a measuring tape. Simple variational statistical processing was applied to the data. In determining the variation of color of coat in the animals from both areas, we used the classification of Adalsteinsson (7).

\section{RESULTS AND DISCUSSION}

The specific exterior features of the Bulgarian screw-horned longhaired goat has impressed German specialists more than 40 years ago -"The impressive thing about this Bulgarian goat, what immediately catches the eye of the observer, are the spirally wounded horns and the richness of colors of coat in these beautiful animals. In both male and female animals, has a spiral and sideways rotated horns. In the bucks, it protrudes widely to the side, is strongly pronounced. The distance from one to the other tip of the horns exceed $90 \mathrm{~cm}$. The shape of the horns and the long hair are characteristic of these animals, so they are intentionally laid down in the name of the breed"(1).

Table 1 presents the most important body measurements of does from the Bulgarian screwhorned longhaired goat breed, from the two native distribution areas.

Table 1. Body measurements of does of the Bulgarian screw-horned longhaired goat in two areas Northwestern Bulgaria ('NWB), and Southwestern Bulgaria (SWB)

\begin{tabular}{|c|c|c|c|c|c|c|c|c|c|c|c|c|}
\hline 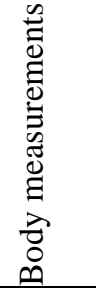 & 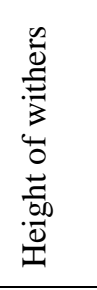 & 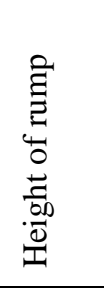 & 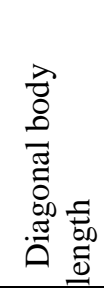 & $\begin{array}{l}\frac{\pi}{0} \\
\frac{7}{3} \\
\overline{0} \\
\frac{0}{0} \\
\frac{0}{n} \\
\end{array}$ & 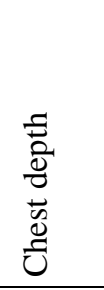 & 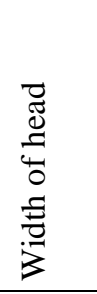 & 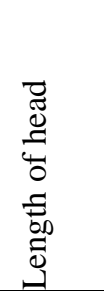 & 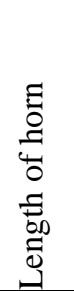 & 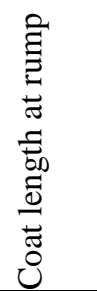 & 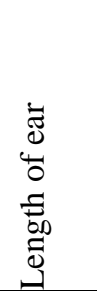 & 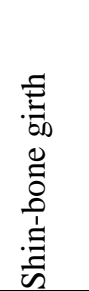 & 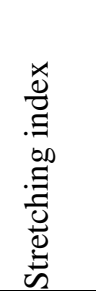 \\
\hline $\begin{array}{l}\text { NWB } \\
\mathrm{n}\end{array}$ & 50 & 50 & 50 & 50 & 50 & 50 & 50 & 50 & 50 & 50 & 50 & 50 \\
\hline$X$ & 74,49 & 73,92 & 79,22 & 23,24 & 35,56 & 14,08 & 21,44 & 41,7 & 18,78 & 15,24 & 9,56 & 106,6 \\
\hline SE & 0,62 & 0,44 & 0,48 & 0,21 & 0,17 & 0,08 & 0,19 & 0,54 & 0,46 & 0,18 & 0,10 & 0,67 \\
\hline $\min$ & 69 & 70 & 71 & 21 & 34 & 13 & 19 & 36 & 14 & 13 & 8 & 101,4 \\
\hline $\max$ & 84 & 80 & 86 & 26 & 38 & 15 & 24 & 48 & 27 & 17 & 11 & 114,4 \\
\hline $\begin{array}{l}\text { SWB } \\
\mathrm{n}\end{array}$ & 50 & 50 & 50 & 50 & 50 & 50 & 50 & 50 & 50 & 50 & 50 & 50 \\
\hline$X$ & 66,06 & 65,86 & 69,84 & 18,08 & 30,52 & 12,64 & 18,26 & 38,9 & 24,66 & 14,0 & 8,05 & 105,7 \\
\hline SE & 0,32 & 0,36 & 0,52 & 0,24 & 0,31 & 0,14 & 0,15 & 0,50 & 0,67 & 0,16 & 0,07 & 0,67 \\
\hline $\min$ & 61 & 60 & 64 & 13 & 21 & 11 & 16 & 32 & 16 & 12 & 7 & 99,5 \\
\hline $\max$ & 71 & 71 & 77 & 23 & 34 & 14 & 21 & 43 & 35 & 16 & 9 & 116,6 \\
\hline $\mathrm{P}$ & $* * *$ & $* * *$ & $* *$ & $* * *$ & $* * *$ & $* *$ & $* * *$ & $* * *$ & $* * *$ & $* * *$ & $* * *$ & $*$ \\
\hline
\end{tabular}


In the comparative study of the exterior in specimens from the two natural distribution areas of the breed, it can be seen that in the region of Vratsa and Botevgrad, the goats have pronounced spiral wounded horns (Figure 1). Horns from aegagrus type, sickle-shaped backwards (so-called "zadnorogy" in Bulgarian), were almost non-existent. Such goats are excluded from the selection of breeders in this region, and they prefer animals whose horns are with the expressed spiral curved, along their longitudinal axis. In the goats from the Blagoevgrad region, specimens with the typical helical winding of the horns also predominate. Goats from aegagrus type were less common, and also, as an exception, there were hornless goats ("shuty" in Bulgarian) (Figure 2). Some individual farmers from Southwestern Bulgaria prefer their goats to have horns of aegagrus type, the so-called "zadnorogy". The reason given by them is that these goats do not get injured in intra-herd conflicts, such as herd hierarchy battles. A similar variation in the type of horns is described by German specialists, in the population of Bulgarian screw-horned goats in Germany. In some female of this breed there are also normal sickle-shaped horns, in which,
VUCHKOV A.

however, the sign of spiral horns is hidden, but can be proved by their offspring with spiral horns (1).

The horns in bucks from both distribution areas were well developed, characteristically spirally wounded along the longitudinal axis. They grow up upright, with a more open angle from the skull. The bucks from the area of Northwestern Bulgaria has more massive and rough horns (Figure 3). The length of horns varies from $43 \mathrm{~cm}$, to $65 \mathrm{~cm}$. Average 53.65 $\mathrm{cm}$. The distance from peak to peak was 76.25 $\mathrm{cm}$. The horns of the bucks from Southwestern Bulgaria were $40.05 \mathrm{~cm}$ long, with a deviation of $33 \mathrm{~cm}$ up to $48 \mathrm{~cm}$. The differences were statistically proven, with a high degree of probability. A similar shape of the horns is observed in some other european native goats breeds. In the endangered French native breed Rove goat, the horns are highly developed in both females and males, with a typical spiral winding along the longitudinal axis (8). Another European goats breeds with a characteristic helical winding of the horns are the Italian local breeds Garganica and Girgentana (9-12).
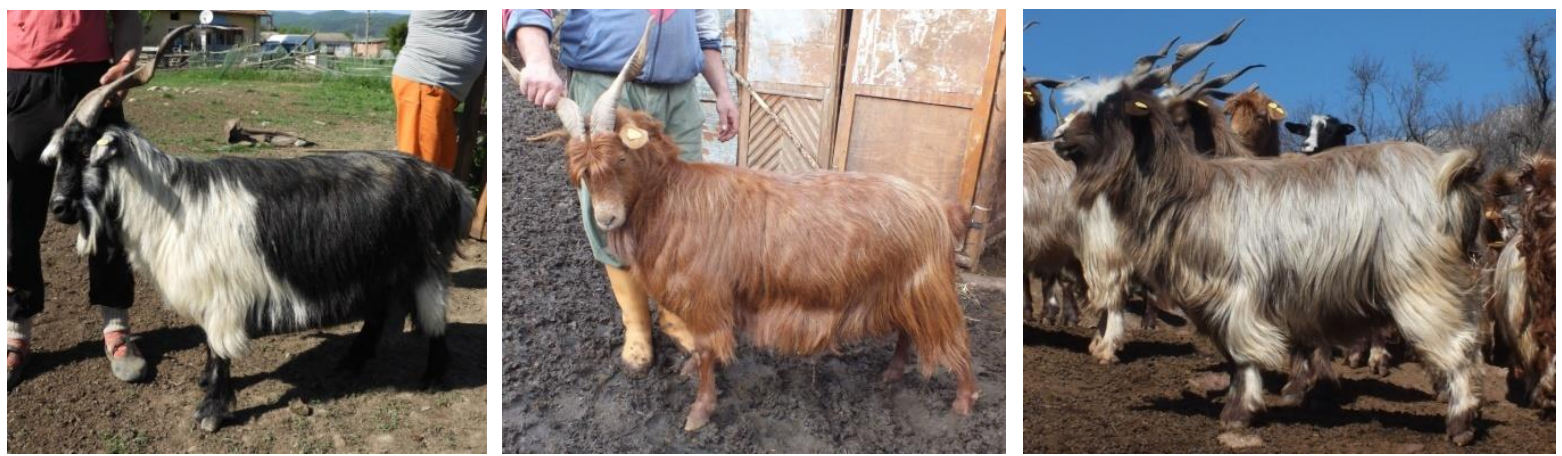

Figure 1. Bulgarian screw-horned longhaired goats from the area of Northwestern Bulgaria (does). (C) Sedefchev.
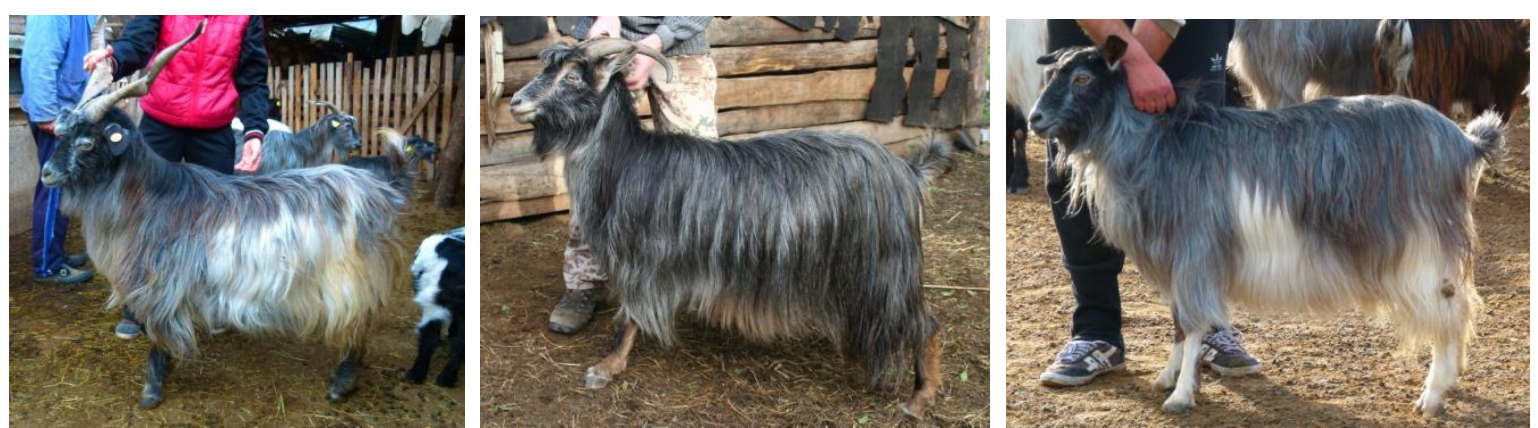

Figure 2. Bulgarian screw-horned longhaired goat from area of Southwestern Bulgaria. Different types of the horns "screw-horned"; "aegagrus"and hornless (does).@ Sedefchev. 

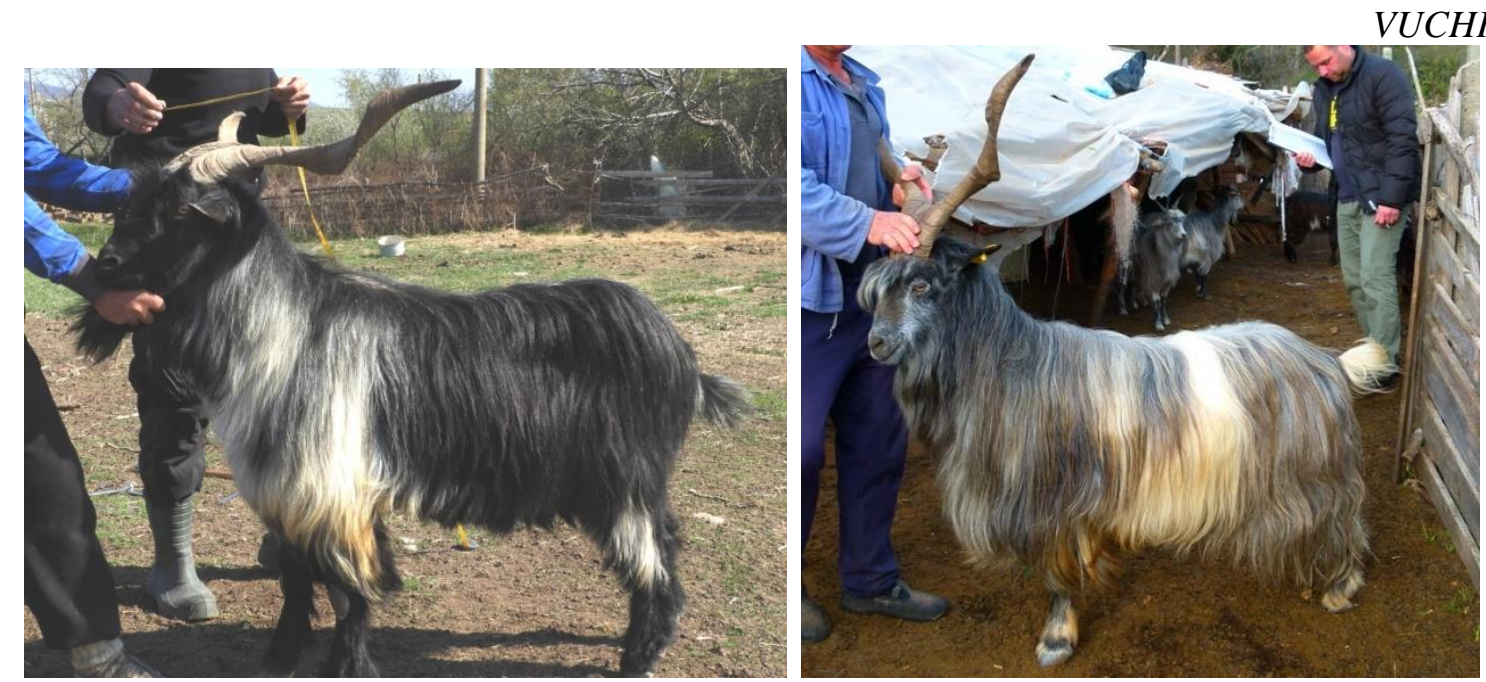

Figure 3. Bulgarian screw-horned longahaired goat (bucks). In left - from the area of Northwestern Bulgaria, in right - from the area of Southwestern Bulgaria.C Sedefchev.

The helical shape of the horns in the Girgentana breed is particularly pronounced. A significant difference with the Bulgarian screw-horned goat is that in Girgentanagoat breed the horns are much coarser, grow almost straight up, when coming out of the skull, and do not deviate to the sides.

The exterior dimensions of specimens from the two distribution areas of the breed, show a clear difference in height. The goats from the northwestern slopes of Stara Planina were significantly larger and more massive. The height at the withers of the does from the Vratsa region wass $74.42 \mathrm{~cm}$. The deviations of this sign vary from 69 to $84 \mathrm{~cm}$. The height at the withers of the does from the Blagoevgrad region wass $66.06 \mathrm{~cm}$, with a variation from 61 to $71 \mathrm{~cm}$. The difference in the average height of female animals from the two areas was almost $9 \mathrm{~cm}$, statistically proven, with a high degree of probability.

Table 2. Body measurements of bucks of the Bulgarian screw-horned longhaired goat in two areas Northwestern Bulgaria ('NWB), and Southwestern Bulgaria (SWB).

\begin{tabular}{|c|c|c|c|c|c|c|c|c|c|c|c|c|}
\hline 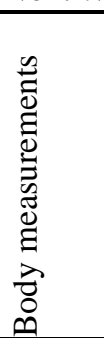 & 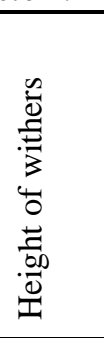 & 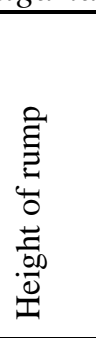 & 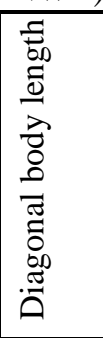 & 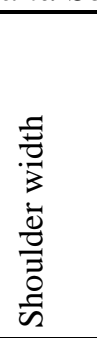 & 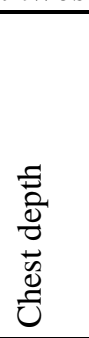 & 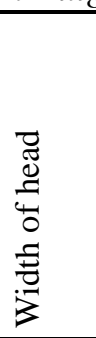 & 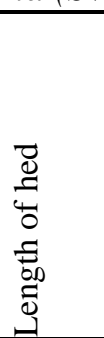 & 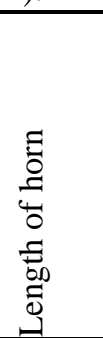 & 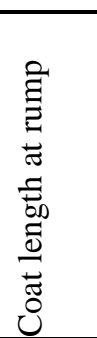 & 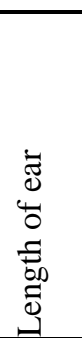 & 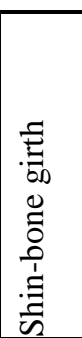 & 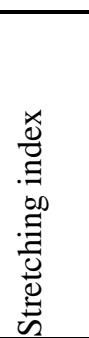 \\
\hline $\begin{array}{l}\text { NWB } \\
n\end{array}$ & 20 & 20 & 20 & 20 & 20 & 20 & 20 & 20 & 20 & 20 & 20 & 20 \\
\hline $\mathrm{X}$ & 83,75 & 81,05 & 86,2 & 27,25 & 39,1 & 16,0 & 24,75 & 53,65 & 28,5 & 14,3 & 11,7 & 102,9 \\
\hline SE & 1,44 & 1,18 & 1,34 & 0,41 & 0,91 & 0,11 & 0,19 & 1,80 & 1,22 & 0,11 & 0,14 & 0,38 \\
\hline $\min$ & 75 & 76 & 80 & 25 & 35 & 15 & 24 & 43 & 22 & 14 & 11 & 101,1 \\
\hline $\max$ & 93 & 90 & 94 & 30 & 45 & 17 & 27 & 65 & 34 & 15 & 13 & 106,6 \\
\hline $\begin{array}{l}\text { NWB } \\
\mathrm{n}\end{array}$ & 20 & 20 & 20 & 20 & 20 & 20 & 20 & 20 & 20 & 20 & 20 & 20 \\
\hline $\mathrm{X}$ & 72,4 & 71,45 & 77,35 & 20,75 & 34,0 & 14,25 & 19,45 & 40,05 & 29,07 & 13,9 & 9,55 & 106,7 \\
\hline SE & 0,32 & 0,47 & 0,73 & 0,56 & 0,64 & 0,23 & 0,19 & 1,01 & 0,79 & 0,16 & 0,22 & 0,89 \\
\hline $\min$ & 69 & 68 & 70 & 17 & 30 & 12 & 18 & 33 & 24 & 12 & 8 & 100,0 \\
\hline $\max$ & 74 & 74 & 81 & 24 & 38 & 16 & 21 & 48 & 35 & 15 & 11 & 112,5 \\
\hline $\mathrm{P}$ & **** & *** & $* *$ & *** & *** & *** & **** & **** & $* * *$ & $*$ & $* * *$ & **** \\
\hline
\end{tabular}


The tendency for higher height at the withers in specimens from the area of Northwestern Bulgaria was preserved in male animals as well (Table 2.). The bucks in this area impress with their size and massiveness. The average height at the withers was $83.75 \mathrm{~cm}$, ranging from $75 \mathrm{~cm}$ to $93 \mathrm{~cm}$. The male specimens from the region of Southwestern Bulgaria have been proven to be lower. The average value of this feature in them was $72.45 \mathrm{~cm}$. similar values for the height at the withers cited some authors in male specimens of local French goat breed - Rove (8).

As a rule, both males and females of the breed from both areas in Bulgaria do not show a higher crup than withers. Another characteristic in the exterior of the Bulgarian screw-horned longhaired goat was the slightly elongated body shape. There is a statistically proven trend in which the bucks from the region of Southwestern Bulgaria have a more stretched format. The stretching index in them was 106.7, and in the bucks from Northwestern Bulgaria it was 102.9. In the does, the values of the stretching index were similar - 106.6, and 105.7 , respectively for the female animals from both areas. When analyzing the dimensions of the head, it is noticeable that both the male and female specimens from the area of Northwestern Bulgaria has longer and coarser heads, compared to the representatives of the breed from the area of Southwestern Bulgaria. The length of the head in goats was $21.44 \mathrm{~cm}$, against $18.26 \mathrm{~cm}$, respectively for both areas. The tendency of this sign was also observed in the bucks. The differences were statistically proven with a high degree of probability. A longer length has been reported in the ears of animals from the region of Northwestern Bulgaria, the differences have been proven with a high degree of reliability.

The measurement of the length of the coat in two topographic areas of the body, it can be seen that both males and females from the region of Northwestern Bulgaria have shorter fur, compared to the animals from the population in Southwestern Bulgaria. When analyzing these results, it is necessary to take into account the old, local tradition for shearing of the local goats in the Vratsa region in late spring. In this way the animals more easily survive in the summer heat. The measurement was made in March, so the fur has grown for a year. In the region of Southwestern Bulgaria, there is no practice for shearing of the goats. An interesting trend was observed in the distribution of the color of the coat in the two areas of distribution of the Bulgarian screw-horned goat. The frequent manifestation of the red-brown color of the coat of the specimens from the region of Northwestern Bulgaria, was impressive. This type of coat coloring, corresponds to the eumelanin type of pigmentation, designated as "brown", according to the classification of Adalsteinsson (7). There are both fully pigmented specimens, and with white spots on the body (areas of depigmentation of the hair cover). This coloration was inherited recessively, and is relatively easy to consolidate by the intra-herd selection, as seen in several herds in this area. The other type of coloration with frequent occurrence in the population of the Northwestern area of the breed, was the so-called "barza" type, or "peacock", according to the classification of Adalsteinsson (7). This type of coat pigmentation occurs in different shades (lighter or darker). Black, and black and white coloration was less common in the population of Vratsa and Botevgrad region. In the Southwestern area of distribution occurs all color variants, typical for the Bulgarian screwhorned longhaired goat. The silver-gray colour was relatively common, with both variants fully pigmented, and white spots on the body. This color was referred to as "striped gray", according to the classification of Adalsteinsson (7).

\section{CONCLUSIONS}

Based on the results obtained from the exterior dimensions of the Bulgarian screw-horned longhaired goats from the two distribution areas - Northwestern Bulgaria, and Southwestern Bulgaria, the following conclusions can be made:

- The Bulgarian screw-horned goats from the area of Northwestern Bulgaria (Vratsa and Botevgrad region), were larger, and more massive, compared to specimens from the population in Southwestern Bulgaria (Petrich and Sandanski region). The height at the withers in females was $74.42 \mathrm{~cm}$, and $66.06 \mathrm{~cm}$, respectively for both areas. For the bucks, the height at the withers was $83.75 \mathrm{~cm}$, and $72.45 \mathrm{~cm}$, respectively. The differences were proven, with a high degree of probability.

- The width and depth of the chests of the does from the area of Northwestern Bulgaria, were $23.24 \mathrm{~cm}$ and $35.56 \mathrm{~cm}$, 
respectively. In the does from the area of Southwestern Bulgaria, the values of these traits were $18.08 \mathrm{~cm}$ and $30.52 \mathrm{~cm}$, respectively.

- The Bulgarian screw-horned goats from Vratsa and Botevgrad region have more massive, and better developed horns, compared to the specimens in the area of Southwestern Bulgaria. In the population from the area of Vratsa and Botevgrad region, the does have pronounced helical shape of horns. Horns with aegagrus type, the so-called "zadnorogy", are almost nonexistent. The bucks from the area of Northwestern Bulgaria, have more massive, and coarse horns. The length has been varied from $43 \mathrm{~cm}$, to $65 \mathrm{~cm}$. Average $53.65 \mathrm{~cm}$. The horns of the bucks from Southwestern Bulgaria were $40.05 \mathrm{~cm}$ long, with a deviation of $33 \mathrm{~cm}$, up to $48 \mathrm{~cm}$.

- The most common colors of the coat in the Bulgarian screw-horned longhaired goats from the area of Northwestern Bulgaria were red-brown color (brown type), and the so-called color "barza" (peacock type). In the population distributed in the area of Southwestern Bulgaria occurs all variants of coloration of the coat, typical for the breed, as the most common distribution was silver-gray color (type striped gray).

\section{REFERENCES}

1. Schuman, A., Die Bulgarische schraubenhörnige Langhaarziege. Arche Nova. 2001.

2. Kalaydzhiev G., A. Vuchkov, T. Angelova, D. Yordanova, V. Karabashev, J. Krastanov, D. Dimov, N. Oblakov, S. Laleva, Y. Popova, Variability of individual coagulation ability and qualitative composition of milk from Local longhaired (screw-horned) goats. International scientific on-line journal "Science \& Technologies”, Publisher "Union of Scientists-Stara Zagora", VolumeIII, Number 5, Animal studies \& Veterinary medicine,. 51-56. 2014.

3. Sedefchev, S., A. Vuchkov, A. Sedefchev. Characterization and preservation of Bulgarian autochthonous breeds of goats. Agricultural Sciences. 6, 67-53. 2011.
VUCHKOV A.

4. Vuchkov, A., D. Dimov, Description and measurement of the exterior of the Bulgarian screw-horned longhaired goatprimary study.Scientific-practical conference - Shumen, Agricultural science, 45 (5-6), 62-68. 2012.

5. Vuchkov A., Dimov D., A comparative analisysis of the exterior in local goat breeds from Southwest Bulgaria. VII International Scientific Agriculture Symposium "Agrosym 2016". 6-9 October 2016, Bosnia and Herzegovina.2271-2279. 2016.

6. Vuchkov A, Kostova M, Bojinov B., Variations of the color of coat in two autohtonous goat breeds in Southwest Bulgaria. Journal of Mountain Agriculture on the Balkans, 20 (5), 25-36. Troyan, Ecomauntin. 2017.

7. Adalsteinsson, S., D. P. Sponenberg, S. Alexieva and A.J.F. Russell. Inheritance of goat coat colors. Journal of Heredity, 85, 267-272. 1994.

8. Bertaglia M., Marc M., Trommetter M. Conserving local goat breeds and traditional pastoralism in southern France. Agricoltura mediterranea. 135. 2005.

9. Criscione A, Bordonaro S, Moltisanti V. Differentiation of South Italian goat breeds in the focus of biodiversity conservation. Small Ruminant Res 145:12-19. 2016.

10.De Marzo D., Jambrenghi A.C., Nicastro F., The Garganica and Girgentana Goat Breeds Reared in Different Regions of Italy. In: Simões J., Gutiérrez C. (eds) Sustainable Goat Production in Adverse Environments: Volume II. Springer, Cham. 2017.

11.Di Grigoli A, Bonanno A, Alabiso M. Effects of housing system on welfare and milk yield and quality of Girgentana goats. Ital J Anim Sci 2(suppl 1):542-544. 2003.

12.Mastrangelo S., Bonanno A. The Girgentana Goat Breed: A Zootechnical Overview on Genetics, Nutrition and Dairy Production Aspects. In: Simões J., Gutiérrez C. (eds) Sustainable Goat Production in Adverse Environments: Volume II. Springer, Cham.2017. 